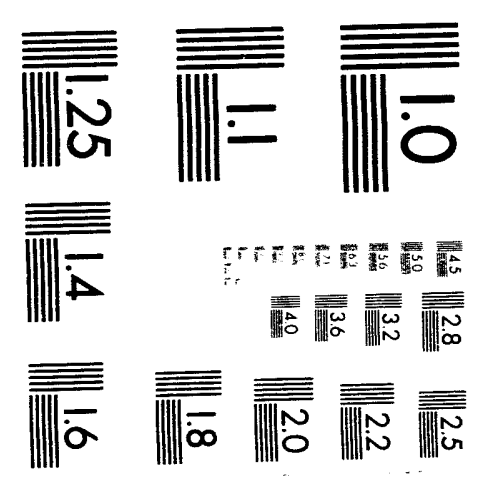



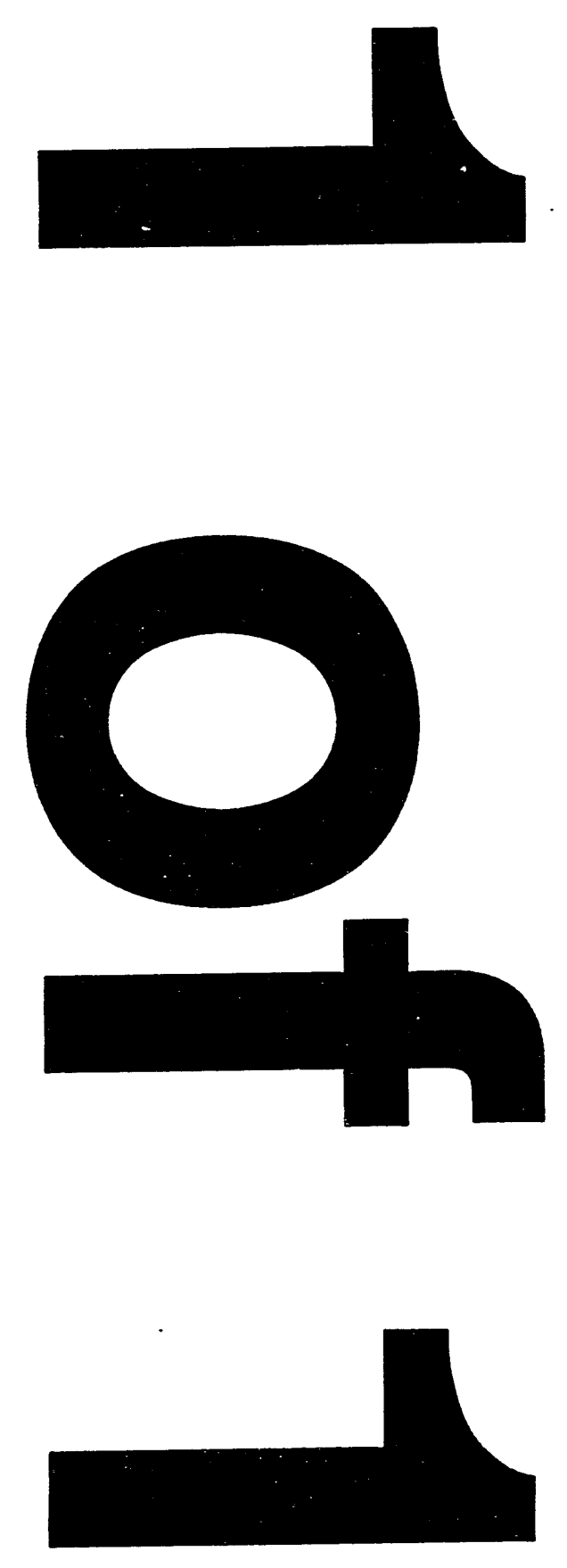


\section{Adaptive Sampling Strategy Support for the Unlined Chromic Acid Pit, Chemical Waste Landfill, Sandia National Laboratories, Albuquerque, New Mexico}

by R.L. Johnson

Environmental Assessment Division,

Argonne National Laboratory, 9700 South Cass Avenue, Argonne, Illinois 60439

November 1993

Work sponsored by United States Department of Energy,

Assistant Secretary for Environmental Restoration and Waste Management 


\section{CONTENTS}

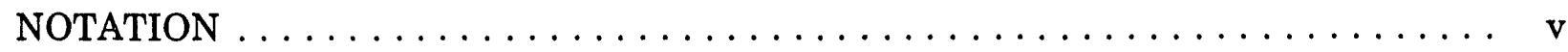

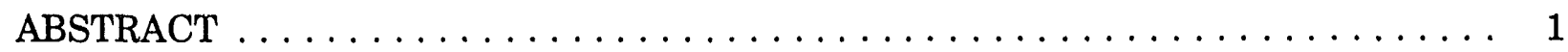

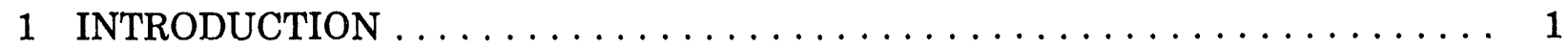

2 QUALITATIVE SUPPORT FOR ADAPTIVE SAMPLING PROGRAMS $\ldots \ldots \ldots \quad 4$

3 QUANTITATIVE SUPPORT FOR ADAPTIVE SAMPLING PROGRAMS $\ldots \ldots \ldots \quad 9$

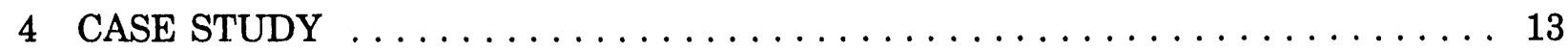

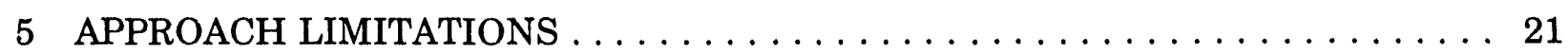

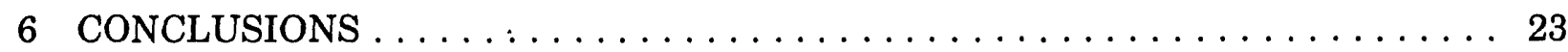

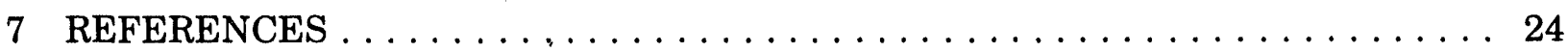

\section{TABLE}

1 Comparison of Available Environmental Data Integration, Management, and Visualization Software Pertinent to Adaptive Sampling Program Support

\section{FIGURES}

1 Framework for Adaptive Sampling Program Support $\ldots \ldots \ldots \ldots \ldots \ldots \ldots$

2 Decision Process for Adaptive Sampling Program Support $\ldots \ldots \ldots \ldots \ldots \ldots 11$

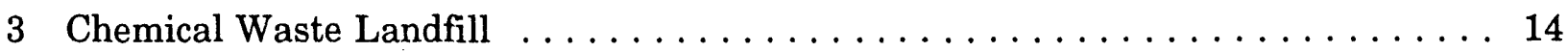

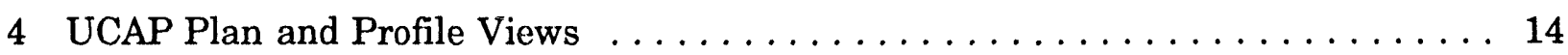

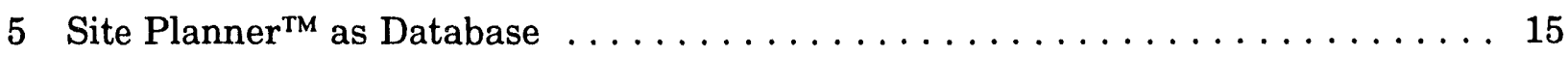

6 Site Planner ${ }^{\mathrm{TM}}$ as Data Visualizer $\ldots \ldots \ldots \ldots \ldots \ldots \ldots \ldots \ldots \ldots \ldots \ldots \ldots$

7 Expected Impact of New Vertical Bores $\ldots \ldots \ldots \ldots \ldots \ldots \ldots \ldots \ldots \ldots$

8 Classification of UCAP Decision Points $\ldots \ldots \ldots \ldots \ldots \ldots \ldots \ldots \ldots \ldots$ 


\section{FIGURES (Cont.)}

9 Lateral Contamination at a Depth of $6 \mathrm{~m} \ldots \ldots \ldots \ldots \ldots \ldots \ldots$

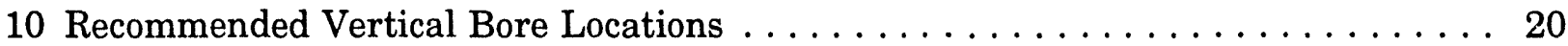




\section{NOTATION}

The following is a list of the acronyms, initialisms, and abbreviations (including units of measure) used in this report.

DQO daia quality objective

EPA U.S. Environmental Protection Agency

f foot (feet)

GIS geographic information system

GUI graphical user interface

m meter(s)

MWLID Mixed Waste Landfill Integrated Demonstration

PC personal computer

pdf probability density function

TEVES Thermally Enhanced Vapor Extraction System

UCAP unlined chromic acid pit 


\title{
ADAPTIVE SAMPLING STRATEGY SUPPORT FOR THE UNLINED CHROMIC ACID PIT, CHEMICAL WASTE LANDFILL, SANDIA NATIONAL LABORATORIES, ALBUQUERQUE, NEW MEXICO
}

by

\author{
R.L. Johnson
}

\begin{abstract}
Adaptive sampling programs offer substantial savings in time and money when assessing hazardous waste sites. Key to some of these savings is the ability to adapt a sampling program to the real-time data generated by an adaptive sampling program. This paper presents a two-prong approach to supporting adaptive sampling programs: a specialized objectoriented database/geographical information system (SitePlanner ${ }^{\mathrm{TM}}$ ) for data fusion, management, and display and combined Bayesian/geostatistical methods (PLUME) for contamination-extent estimation and sample location selection. This approach is applied in a retrospective study of a subsurface chromium plume at Sandia National Laboratories' chemical waste landfill. Retrospective analyses suggest the potential for characterization cost savings on the order of $60 \%$ through a reduction in the number of sampling programs, total number of soil boreholes, and number of samples analyzed from each borehole.
\end{abstract}

\section{INTRODUCTION}

Characterizing hazardous waste sites is an expensive and time-consuming process that typically involves successive sampling programs. The total cost per sample can be prohibitive when sampling program mobilization costs, drilling or borehole expenses, and sample analysis costs are all included. Adaptive sampling programs present the potential for substantial savings in the time and cost associated with characterizing a site. Adaptive sampling programs use recent advances in sensor technologies to generate real-time information on the extent and level of contamination. This information can take the form of nonintrusive geophysical survey results, down-hole and cross-bore sensor information, and field laboratory data. By using field laboratory techniques, adaptive sampling programs reduce the cost per unit of information collected. By using information that is generated and analyzed in real time, sampling programs can be guided interactively, thereby reducing the number of samples to only those absolutely necessary to satisfy characterization needs. Finally, site characterization based on adaptive sampling programs can often be brought to closure after one or two field visits, thus eliminating the mobilization costs associated with 
the staged, repetitive characterization approach traditionally used. Mobilization costs can be significant, including safety and health compliance documentation, field work plans, and final reporting requirements.

In adaptive sampling programs, "adaptive" refers to the ability to change or adapt a program while underway to accommodate new data as they are being generated. Adaptive sampling programs demand a means of rapidly integrating, visualizing, and analyzing data. This report describes the combined application of a commercial object-oriented database/geographic information system (SitePlanner ${ }^{\mathrm{TM}}$ ) specifically designed for site assessment work and a smart sampling strategy methodology (PLUME) to the problem of supporting decision making in adaptive sampling programs (Figure 1). SitePlanner ${ }^{\mathrm{TM}}$ provides real-time data fusion, management, and visualization. In this role, SitePlanner ${ }^{\mathrm{TM}}$ offers an immediate, qualitative image of where contamination might be expected and how it is spatially related to other site features such as the water table and geological strata. PLUME quantitatively fuses "hard" (i.e., sample results) and "soft" (e.g., historical information, past experience, and nonintrusive survey results) information regarding contamination extent, estimates the extent of contamination and the uncertainty associated with those estimates, measures the expected impact derived from obtaining additional samples, and finds the best new sampling locations. In this role, PLUME provides quantitative support for adaptive sampling programs.

This approach was demonstrated as part of the Mixed Waste Landfill Integrated Demonstration (MWLID) at an unlined chromic acid pit (UCAP) in Sandia National Laboratories' chemical waste landfill. The MWLID is sponsored by the U.S. Department of Energy's Office of Technology and Development, which is part of the Office of Environmental Restoration and Waste Management. The particular contamination event addressed was a chromic acid plume that had developed beneath the UCAP. In addition to past characterization efforts at the site by Sandia National Laboratories' environmental restoration program, a significant amount of data was collected as part of the MWLID. A

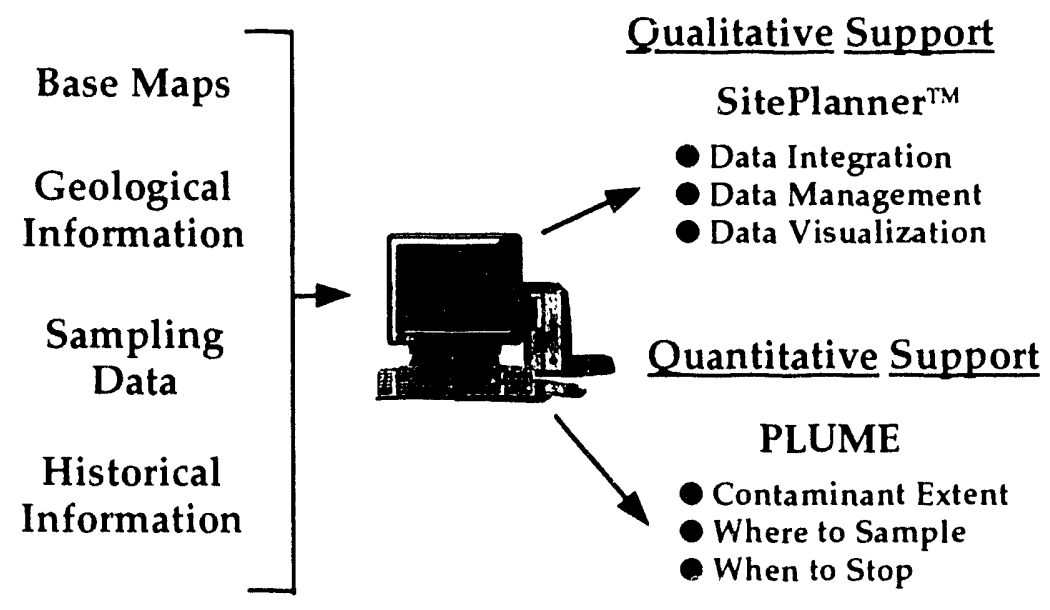

FIGURE 1 Framework for Adaptive Sampling Program Support 
retrospective study was performed that looked at the cost savings that might have been realized if an adaptive sampling program approach had been used at the UCAP site from the start of the characterization process. 


\section{QUALITATIVE SUPPORT FOR ADAPTIVE SAMPLING PROGRAMS}

Environmental restoration decision making is based on conceptual models of hazardous waste sites. Conceptual models are built from qualitative insight derived from site data and quantitative numerical analysis of that data. While quantitative analytical modeling is important to the development of good site conceptual models, the best decisions are those arising first of all from an intimate qualitative understanding of the site. Attaining an intimate understanding of a site is complicated by the nature of hazardous waste site data. These data are complex: they come from a variety of sources; their spatial and temporal components are very important; they address a diverse set of site parameters and processes; their sheer volume can be overwhelming; and they are often incomplete, at times inaccurate, and sometimes completely wrong. Adaptive sampling programs add to the difficulty by demanding real-time data assimilation and synthesis.

The most efficient way for decision makers to understand their data, and ultimately their site, is through visual displays. Past approaches to data integration, management, and visualization have revolved around data archiving systems for data management and standard geographic information systems (GISs) for displaying data with spatial attributes. While data archiving systems and standard GIS applications have an important role to play in site restoration activities, they have fundamental limitations in the context of adaptive sampling programs. Traditional data archiving systems are typically built around relational database packages. These systems are meant to preserve information and guarantee its quality, security, and integrity. Before data are entered into such systems, they must satisfy lengthy quality assurance and quality control procedures. Once entered, access is controlled. Environmental data archiving systems seldom provide users anything more than tabular aggregates of data for analysis.

Standard GIS applications enhance data archiving systems by allowing the display of spatially oriented data in maps. However, these applications also have inherent limitations in the context of adaptive sampling programs. Raster-based GIS systems are ideal for data that are rich in location but sparse in data available at each location (i.e., satellite imagery). Site characterization data are typically sparse in 'ocation but rich in information at each location. For example, a particular site may have a handful of soil boreholes, but the information available at each borehole may include stratigraphic data, down-hole sensor results, and laboratory results for soil samples. Site characterization data are also typically three-dimensional in spatial location. Traditional GIS systems treat data as two-dimensional layers, thus making it hard to visualize three-dimensional subsurface structures such as contaminant plumes and stratigraphic features. Because of the type of data generated by adaptive sampling programs, specialized graphics are required that include bore logs, fence diagrams, and profile views, in addition to the plan views created by standard GIS systems. Finally, most GIS systems are designed primarily for data display and not data management. Consequently, most GIS systems have very limited inherent data management facilities. 
Adaptive sampling programs demand data integration, management, and visualization that is "dynamic," "graphically based," and "interactive." A "dynamic" data integration, management, and visualization system is one whose graphics are dynamically linked to the underlying data. As new data are included or old data changed, the graphics displaying those pieces of data are automatically updated. This capability is important for adaptive sampling programs in which data are continually being generated and images of the site must immediately reflect all available data.

"Graphically based" means that all data can be displayed and manipulated in some visually meaningful way. This includes both individual pieces of data, such as samples or soil cores, and also graphics that integrate information from several sources. These integrated graphics might take the form of plan views of the site, profile views showing subsurface characteristics, bore logs, fence diagrams, time views, or whatever is pertinent to the characterization. Such graphics are valuable because they can show the spatial and temporal relationships between different objects. An example is the spatial relationship between the location of contaminated samples and the water table, specific stratigraphic features, or potential risk receptors such as a municipal well field.

Finally, "interactive" means that the decision maker has easy access to data contained in displays, and that the processes required for incorporating new data and generating new displays are quickly learned and simple to execute. Implied in the use of the term interactive is a menu-, mouse-, and icon-driven system based on a standard graphical user interface (GUI) that is easy to learn and easy to use. The paradigm of centralized computing facilities does not fit into an adaptive sampling program. Technical staff directing an adaptive sampling program will likely have considerable expertise as geologists, hydrologists, or geochemists but will probably have limited computer knowledge. They are, however, the ones that need access to data and graphics.

As part of the MWLID, a review was conducted of commercial and public-domain software packages available at the time of this report. The results of this review are presented in Table 1. Table 1 is not comprehensive, but it does span the range of capabilities presently available. Software packages fall generally into two categories: those based on personal computer (PC) technology and those developed around workstation technologies. PC-based software packages tend to be cheaper and more limited in their graphical capabilities. Workstation-based technologies tend to be significantly more expensive but have significantly greater data visualization capabilities. It is important to note that both software and hardware capabilities are rapidly evolving. Several of the packages listed in Table 1 were unavailable at the start of the MWLLD, while others have undergone remarkable improvements in the last 12 months.

The categories used to rate packages were ease of use, database capabilities, data visualization, and modeling capabilities. The issues addressed under ease of use included whether a package is mouse/menu or command driven, uses accepted GUI standards, has completely internal capabilities or requires other packages, uses generic or specialized 
TABLE 1 Comparison of Available Environmental Data Integration, Management, and Visualization Software Pertinent to Adaptive Sampling Program Support

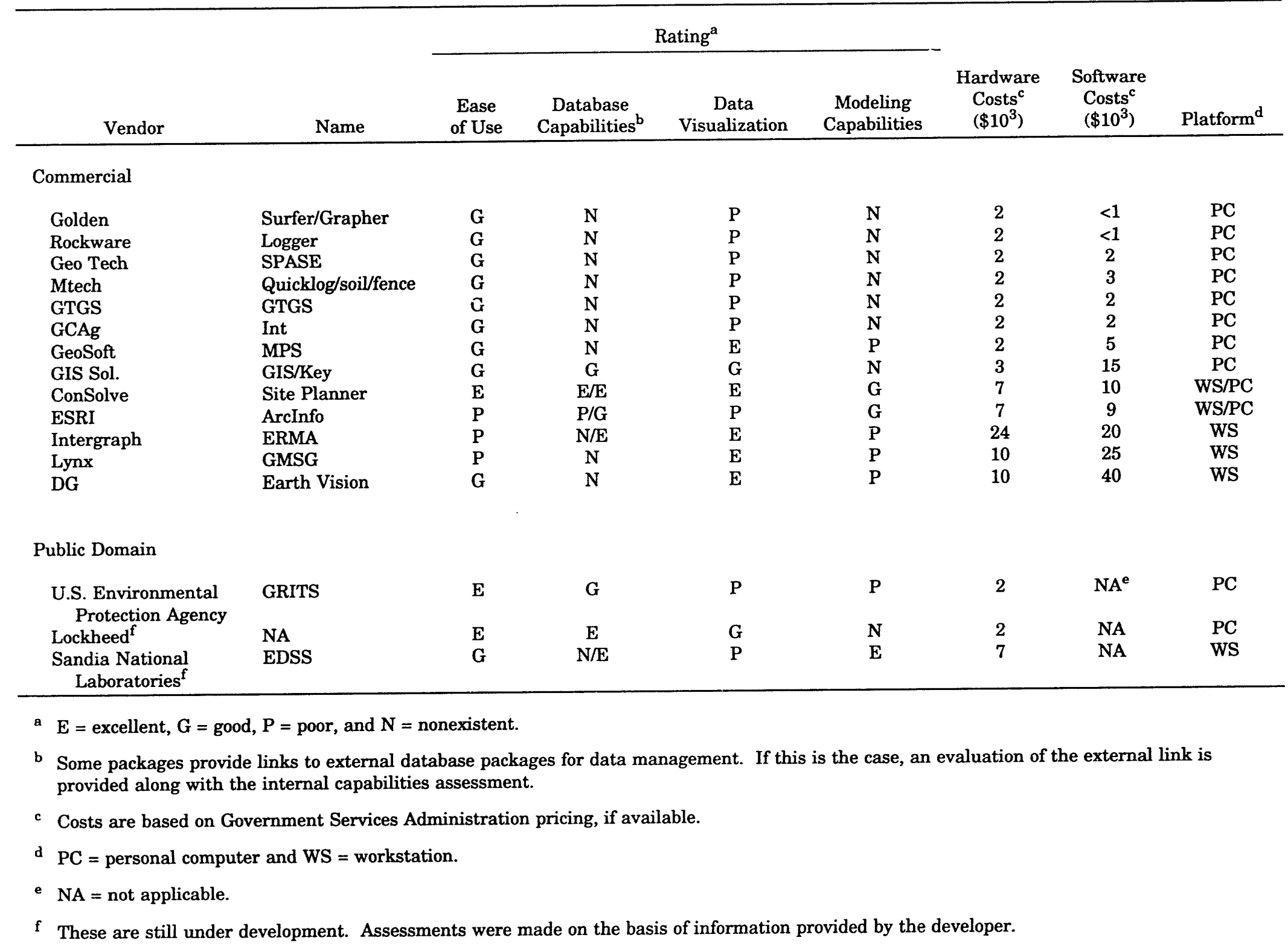


hardware, and finally whether it communicates easily with other software packages. The issues addressed under database capabilities include whether a package has internal, fully functional, extensible database capabilities or has to rely on other database programs for these capabilities. In the latter instance, the issue is how easily the package is connected to databases and how seamless the connection appears to the user. The issues addressed under data visualization include whether a complete suite of specialized graphics required by site characterization/restoration programs are provided, whether graphics are dynamically connected to underlying data, and whether graphics can be generated quickly. The final modeling category recognizes that environmental restoration decision making will need to be supported by quantitative analysis. The issue is whether the software packages include significant analytical capabilities themselves or provide direct links that allow analytical capabilities to be easily attached.

Software and hardware costs are issues specific to adaptive sampling program support and more generally in the realm of environmental decision making. The costs and complexity of traditional data archiving systems and GIS have placed these systems in the realm of centralized computing. Analysis and decision making for environmental restoration is a decentralized process. The best decision-making support occurs on the decision maker's desktop or out in the field trailer (as in the case of adaptive sampling programs). This means that software must not only be usable by the average technical person but also financially accessible. While most PC packages are attractive from a cost perspective, they fall short in capabilities. Workstation technologies have traditionally excelled in capabilities but have been far too expensive to place on decision makers' desktops.

For the purposes of the MWLID, SitePlanner ${ }^{\mathrm{TM}}$ was selected for demonstration. At the start of the MWLID in 1991, SitePlanner ${ }^{\text {TM }}$ was still in the development stage but from a capabilities and cost standpoint it showed the most promise for adaptive sampling program support. SitePlanner ${ }^{\mathrm{TM}}$ is an object-oriented database specifically designed for site characterization work. It was developed by ConSolve, Inc. Object-oriented data management systems organize information by object rather than by table. Object classes are defined in an object dictionary, and as new data are included, new instances of a particular object class are created. Examples of object classes for adaptive sampling programs are soil boreholes and soil samples. The power of object-oriented databases lies in the ability of new objects to inherit the attributes associated with their class definition. One example of this inheritance is the set of data fields that needs to be filled for a particular object class as new instances of that class are created. Another example of inheritance is the display capabilities associated with an object class. For example, a soil borehole might possess the ability to participate in the creation of a bore log, but a lagoon would not. Or, a series of water samples taken from the same well over a period of time might be displayed in a "time view," but a set of soil boreholes could not.

Because SitePlanner ${ }^{\mathrm{TM}}$ is first of all a database, many of the standard database functions are inherently present, including the ability to do complicated queries and to have immediate access to site data. Objects are visually displayed in the various graphics as icons. These icons can be selected individually or as aggregates, and their data can be displayed. 
Because the data dictionary is extensible, the types of objects and their data fields can be defined to meet the needs of the site undergoing characterization or restoration. SitePlanner ${ }^{\mathrm{TM}}$ provides a variety of graphics, including plan views, profile views, fence diagrams, bore logs, and contaminant surfaces. All of these are dynamically linked to the underlying database and can be created quickly. The user interface for SitePlanner ${ }^{\mathrm{TM}}$ is based on the Sun OpenWindows GUI and is consistent with all other OpenWindows software available for Sun workstations. The base hardware configuration for SitePlanner ${ }^{\mathrm{TM}}$ is a Sun IPX or LX desktop workstation, or a PC 486 with SCO ${ }^{\mathrm{TM}}$ Unix. 


\section{QUANTITATIVE SUPPORT FOR ADAPTIVE SAMPLING PROGRAMS}

Contaminated areas generally possess two key characteristics. First, they include spatial processes that are dominated statistically by spatial autocorrelation. This simply means that the results from one sampling location will be similar to results from a neighboring sampled point but may differ completely from a third sample taken farther away. Second, typically substantial soft information exists regarding probable contamination extent, even if few hard sample data are initially available. This information might come from past experience with similar sites, from historical records documenting release size, from nonintrusive geophysical surveys, or from preliminary transport modeling results.

Quantitative support for adaptive sampling programs should provide estimates of contaminant extent, measures of the uncertainty associated with those estimates, indications of how much additional information might be gained from further sampling, and direction as to where additional samples should be placed so as to maximize the value of the information they produce. To do this, quantitative sampling strategy support must accommodate spatial autocorrelation present in sampling results and somehow quantitatively merge existing soft information with hard sample data as it is produced by an adaptive sampling program. Bayesian analysis provides a natural framework for quantitatively fusing hard and soft data, while spatial statistical analysis can help with incorporating spatial autocorrelation.

Bayesian analysis is rooted in Bayes Theorem:

$$
P(X \mid Y)=P(X) \cdot P(Y \mid X)
$$

Equation 1 says that the probability of encountering state $X$ given a set of $Y$ values is proportional to the product of the probability of state $X$ and the probability of encountering the set of $Y$ values given state $X$. The function $P(X)$ is called the prior probability density function (pdf) for $X$, and $P(X \mid Y)$ is called the posterior pdf. In the context of sampling to delineate contamination, $P(X)$ is associated with the probability of contamination extent before samples are taken, and $P(X \mid Y)$ is its probability given the results of sampling. A prior pdf such as $P(X)$ could be constructed out of either hard or soft information. Bayes Theorem provides the mechanism for quantitatively updating $P(X)$ with new sampling information.

To apply a Bayesian approach to delineating contamination events, one must interpolate from points where sampling data exist to areas where samples have not been collected. Spatial autocorrelation provides the rationale for interpolation; spatial statistical techniques provide the mechanism. Kriging is an interpolation procedure based on spatial statistical analysis. Kriging provides the "best" linear interpolated value at an unsampled point given a set of sampled points, where best is defined as the unbiased estimate with the least expected estimation error. If one is delineating contamination events, indicator kriging is appropriate. Indicator kriging considers just the presence or absence of contamination above a prespecified threshold. Indicator kriging has several advantages over ordinary 
kriging in the context of contaminant delineation: ${ }^{1}$ it can work with indicator data generated by field screening technologies; the variograms it uses tend to be more robust; and its interpolated values are also immune to outlying data points.

The first step in applying a Bayesian approach is to define a grid of decision points over a region of interest. As a sampling program develops, one will want to assign a probability of contamination to each point and ultimately decide if the point is contaminated. One can initially define at each point a Beta distribution for the probability of contamination. In the context of Bernoulli trials, Beta distributions are conjugate priors, which means that as new samples are collected and the Beta distributions at each decision point are updated, the results are posterior pdfs that are also Beta distributions with changed parameters. If a decision point is sampled, the probability of contamination at that point will be either zero or one depending on the results of the sampling. If a decision point is not sampled but new samples were taken close by, indicator kriging is used to apply the results of those samples to the particular decision point under consideration to obtain an updated value of its probability of contamination. The details of this updating process can be found in Johnson. ${ }^{2}$

The probabilities of contamination at each decision point can be used to classify whether the point should be considered contaminated, clean, or state uncertain. For example, every decision point whose probability of contamination is greater than 0.8 might be considered contaminated, with probability of contamination less than 0.2 as clean, and with probability of contamination hetween those two values as uncertain. A natural choice for measuring the impact of additional sampling points with this classification system would be to calculate the expected effect a new sampling point would have on the total number of decision points classified as state uncertain - the more decision points expected to be pushed from state uncertain to the clean or contaminated categories, the greater the expected impact. One could then look for the sampling location or set of locations that maximize this impact and direct an adaptive sampling program on the basis of the search results. Figure 2 shows the logical flow of this process.

Defensible stopping criteria are lacking at this point - criteria that would allow the manager of an adaptive sampling program to decide when enough information had been gathered. Sampling program stopping criteria are the natural product of a rational decisionmaking process. The decision-making framework used here is based on U.S. Environmental Protection Agency (EPA) Data Quality Objectives (DQOs). ${ }^{3,4}$ The DQO process consists of basically four steps. First, DQOs define the problem or issue to be addressed by a sampling program. Second, DQOs establish a decision that will be made on the basis of data collected by the sampling program. Third, DQOs determine the level of uncertainty that is allowable when making this decision. Finally, DQOs develop quantitative links between the information generated by the sampling program and the uncertainty associated with the decision to be made. An adaptive sampling program stopping criterion then follows naturally: when the uncertainty associated with decision making is within acceptable bounds, stop sampling. 


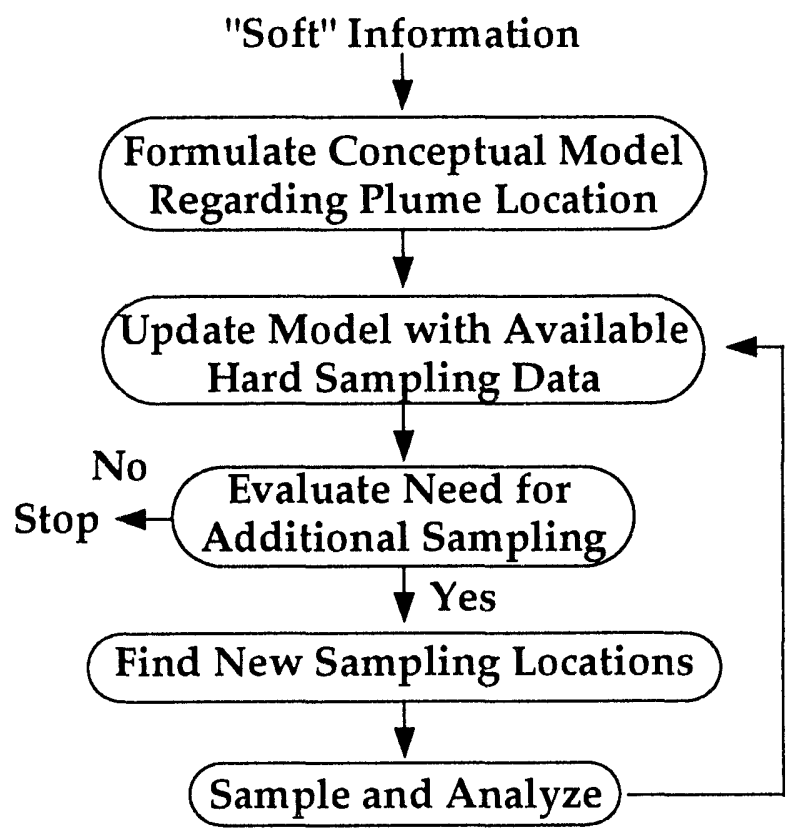

FIGURE 2 Decision Process for Adaptive Sampling Program Support

DQOs measure uncertainty in terms of the probabilities of making a Type $I$ or Type II error. In terms of classical statistical hypothesis testing, a Type I error occurs when one rejects a hypothesis when in fact it is true. Conversely, a Type II error occurs when one accepts a hypothesis that is in fact false. The probability of making either type of error is reduced by collecting more information, although the nature of the information collected may change depending on which error is of greater concern.

The following two examples illustrate how DQOs work. The party responsible for a contaminated site believes that it poses no significant human health risk. The decision that must be made is whether or not the site poses a human health risk. If it does not, then the responsible party can propose no further action. The regulatory agency believes that the available site data are insufficient to support a no-further-action decision; that is, there is too great a chance that the site poses a risk, given what is currently known. In a sampling program, the responsible party wants to make sure that enough information is collected to ensure that the chances of the site being classified as a health risk are unlikely (Type I error). Likewise, the regulatory agency wants to ensure that enough information is collected that the chances of falsely classifying the site as posing no risk are minimal (Type II error). Since the responsible party will be paying for the site characterization, it wants to collect as little data as possible while still satisfying itself and the regulatory agency. Negotiations between the responsible party and the regulator determine the level of uncertainty that is mutually acceptable. The quantitative links between sampling data (which assist in determining extent and level of contamination) and decision-making uncertainty are a combination of geostatistics and risk assessment methodologies. Sampling stops when the 
site can be classified as either requiring no further action or as posing a significant health risk, on the basis of the preagreed-upon level of certainty.

As a second example, suppose that a site has contaminated soils with enough evidence presently available to clearly indicate that the site is a human health risk. The preferred remedial action is excavation and bioremediation. The decision that needs to be made for treatable volumes of soil (i.e., dump truck capacity) is whether they contain contamination above a prespecified threshold. The responsible party and the regulator negotiate to determine mutually acceptable levels of uncertainty associated with classifying a large amount of soil as either clean or contaminated. The quantitative links between sampling data and decision making are based on geostatistics. Sampling in each treatable volume proceeds until that volume can be classified as either contaminated or clean.

While the decisions to be made from data generated by a site characterization vary, they always hinge at least in part on the estimated extent of contamination present and the uncertainty associated with that estimate. The combined Bayesian/geostatistical approach developed for the MWLID supplies the probability of contamination being present at any point in space and so provides natural support for stopping criteria based on DQO analysis. This combined Bayesian/geostatistical approach to quantitative adaptive sampling strategy support is embodied in PLUME, which is a software package developed at Argonne National Laboratory with funding from the MWLID. PLUME merges soft and hard information regarding contamination location, estimates the extent of contamination, measures the uncertainty associated with those estimates, measures the expected reduction in uncertainty to be gained from additional sampling, and indicates where new samples should be taken to maximize the information gained from them. PLUME was designed to complement capabilities of SitePlanner ${ }^{\mathrm{TM}}$. PLUME uses SitePlanner ${ }^{\mathrm{TM}}$ for data management and visualization. 


\section{CASE STUDY}

SitePlanner ${ }^{\mathrm{TM}}$ and PLUME were applied in a retrospective study to the delineation of a chromic acid plume underneath a UCAP within the chemical waste landfill at Sandia National Laboratories, Albuquerque, New Mexico, as part of the MWLID. Figure 3 shows the relative location of the UCAP within the chemical waste landfill. Figure 4 shows a plan view of the immediate vicinity of the UCAP and a profile view of an east-west transect of the pit based on information collected from seven soil boreholes completed in 1987 . The shaded area in the profile view shows the approximate extent, based on sampling results from the 1987 boreholes, of chromium contamination in this east-west transect. When work associated with the MWLID was started in 1992, no information was available on the north-south extent of contamination or its current depth of penetration.

Establishing stopping criteria for adaptive sampling programs requires a decisionmaking framework similar to the DQO process described in Section 3. A number of drilling programs have taken place at the UCAP, beginning in 1981 and ending in 1992. Each of these programs had a variety of purposes, although all shared the ultimate goal of site characterization. To keep the retrospective comparison of what was done to what might have been done as true and simple as possible, the overarching purpose of these characterization programs will be defined as determining the volume of soil contaminated by chromium. Because no stopping criteria were established for the actual drilling programs, the retrospective study will simply compare the uncertainty associated with contaminated volume characterization based on data actually taken to the uncertainty that would have resulted from an adaptive sampling program.

The first step in applying PLUME to the UCAP was to garner all historical data available for the UCAP and integrate them using SitePlanner ${ }^{\mathrm{TM}}$. The object dictionary used by SitePlanner ${ }^{\mathrm{TM}}$ was modified to handle the soil boreholes, monitoring wells, landfills, directionally drilled boreholes, and soil samples expected to be included. A SitePlanner ${ }^{\mathrm{TM}}$ virtual site was then constructed from base maps for the chemical waste landfill extracted from ArcInfo ${ }^{\mathrm{TM}}$ coverages, monitoring well information (construction data, stratigraphic data, depth to water table measurements, etc.), and existing soil borehole and sample information. Once the base virtual site was created, SitePlanner ${ }^{\mathrm{TM}}$ was ready to accept additional data as new boreholes were sunk and additional samples collected and analyzed by the MWLID.

SitePlanner ${ }^{\mathrm{TM}}$ played three key roles: database, data visualization, and reality check

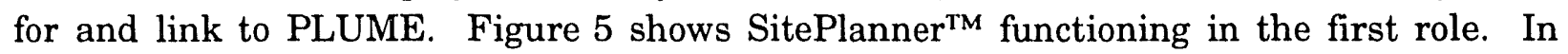
Figure 5, soil borehole UCAP-3 has been selected and its data displayed. From the scrolling list of objects attached to this borehole, soil sample 10073 has been selected and its data retrieved, including both locational information and chemical results. Figure 6 is an example of data visualization. In Figure 6, a bore log, profile view, and fence diagram provide subsurface pictures of stratigraphic structure and contamination location. In every view, objects are represented by icons that are immediately available for selection and data display. For example, in the bore log, profile view, and fence diagram, the icons running the length of the boreholes indicate the locations of soil sample objects. 


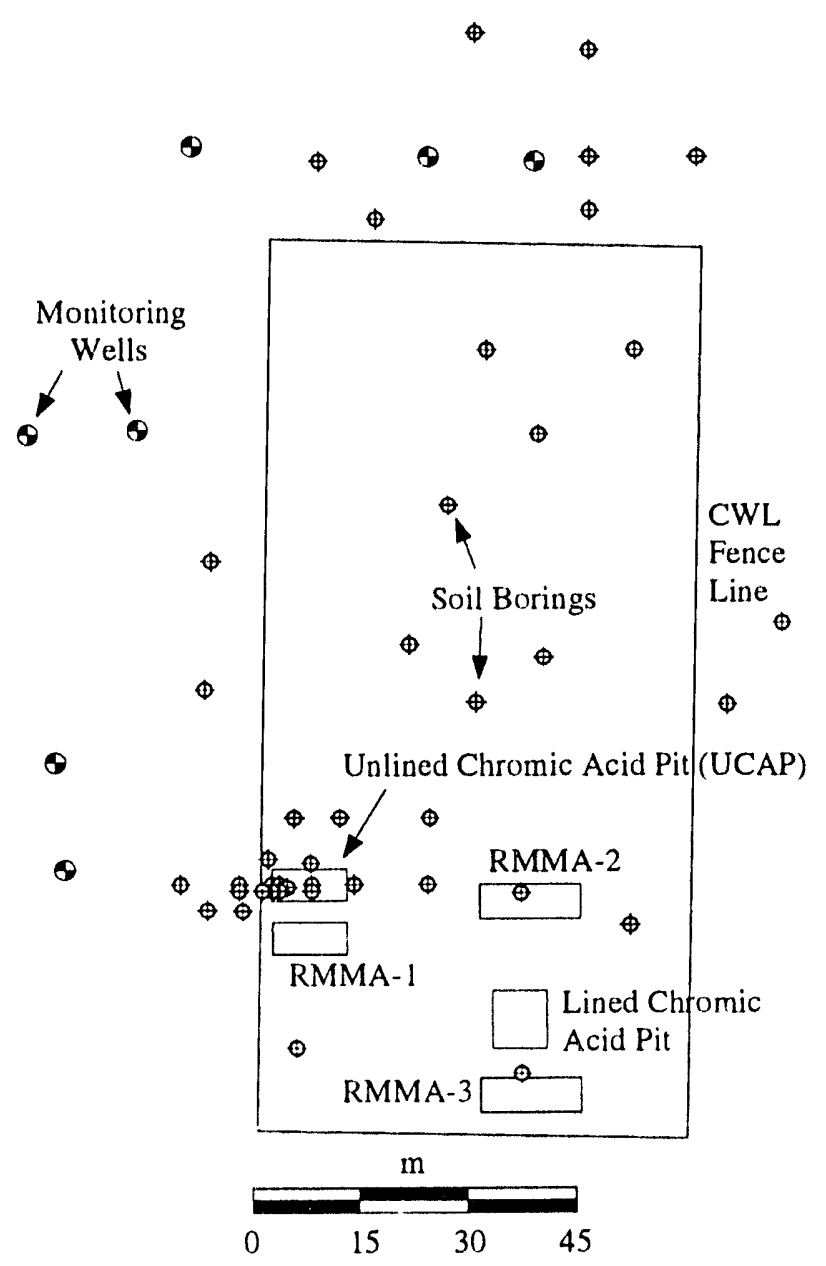

FIGURE 3 Chemical Waste Landfill
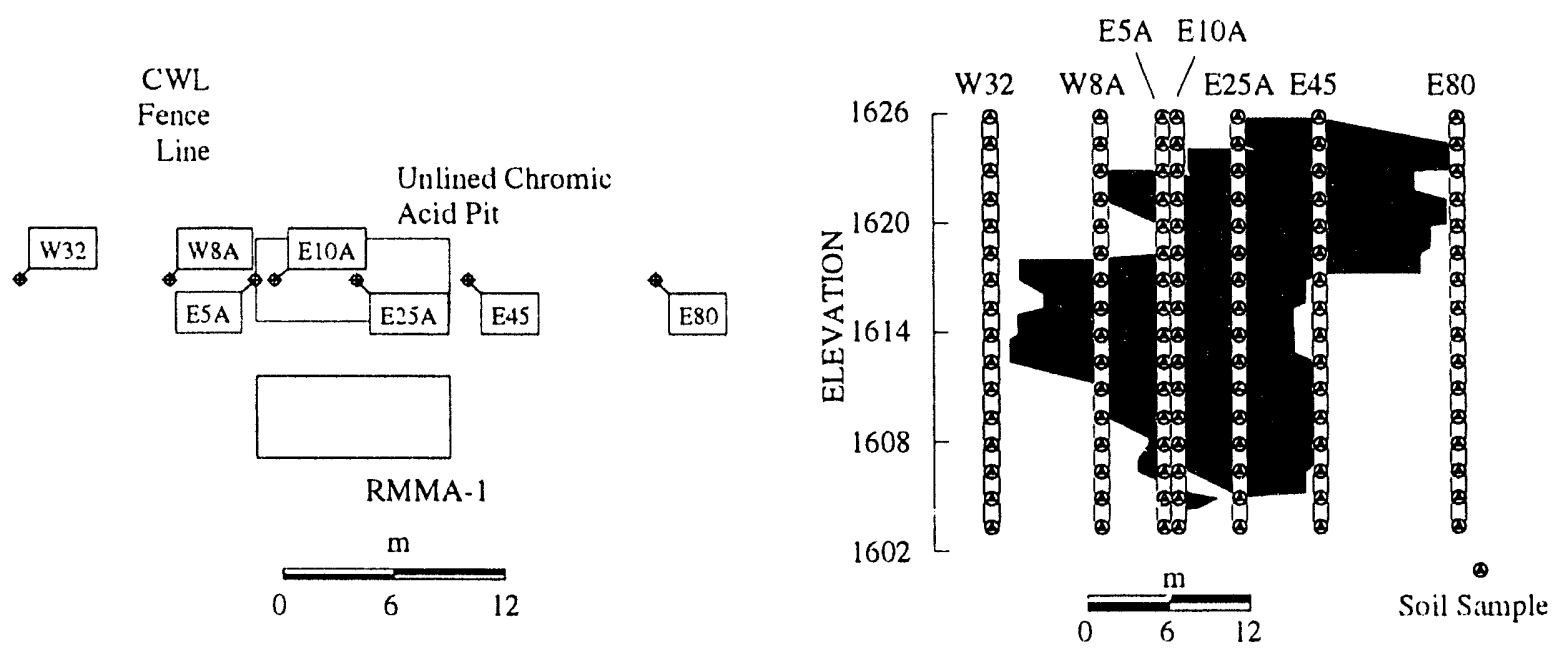

FIGURE 4 UCAP Plan and Profile Views 


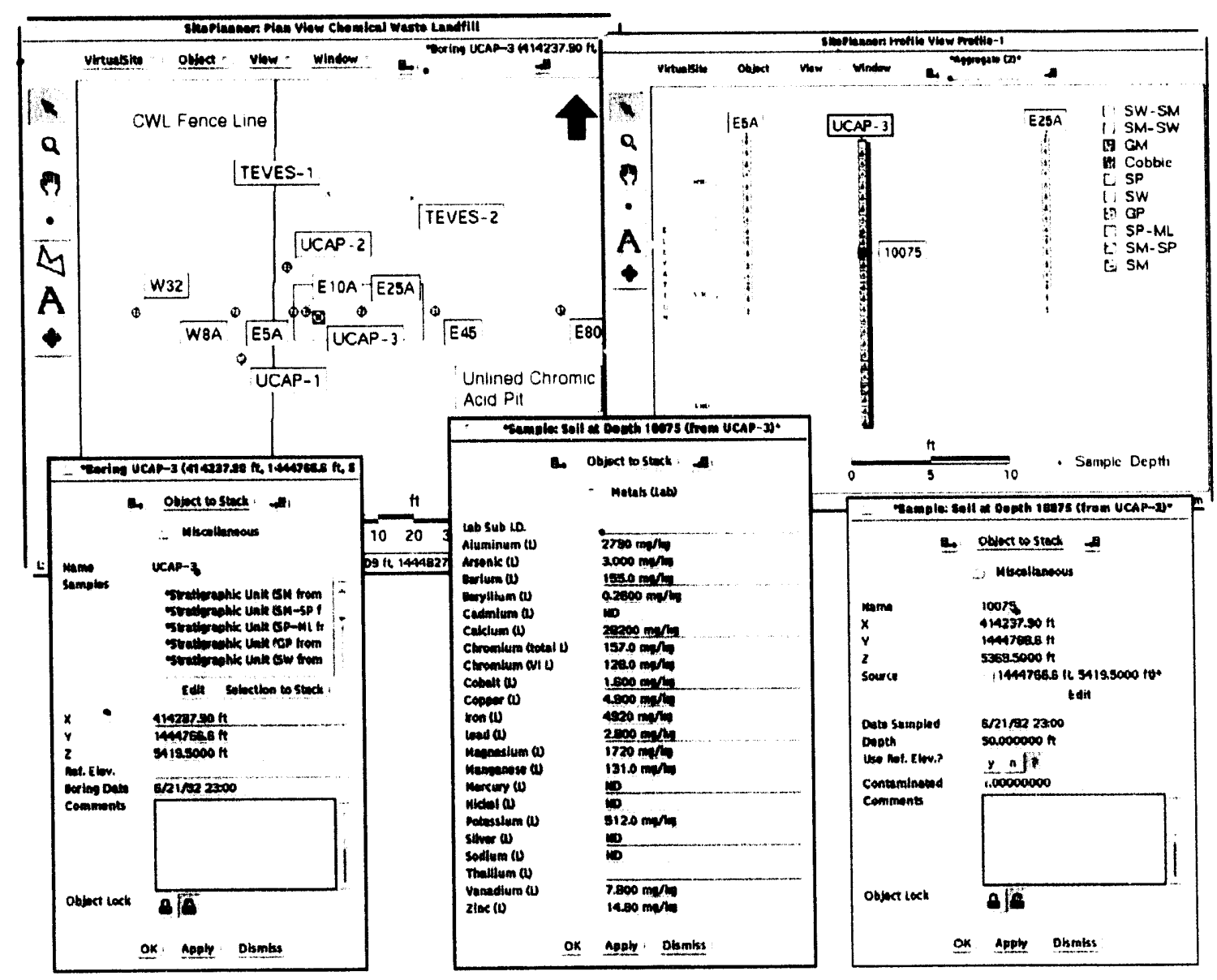

FIGURE 5 Site Planner ${ }^{\mathrm{TM}}$ as Database

The initial goal of the MWLID sampling program was to determine the best new vertical borehole locations for delineating the extent of the chromium contamination and to position sampling points along those boreholes, given the data that already existed for the UCAP. These data consisted primarily of information from three sampling programs conducted in the 1980s, a single borehole completed within the pit in 1981, four boreholes completed on a limited east-west transect in 1983, and seven boreholes completed on a more ambitious transect in 1987. To facilitate the analysis, a three-dimensional grid of decision points was superimposed over the region of interest -16 points along the east-west axis, 16 points along the north-south axis, and 15 along the vertical axis, for a total of 3,840 decision points, with $2.1 \mathrm{~m}(8 \mathrm{ft})$ separating each point. The extent of this grid was based on the belief that it completely encompassed any potential contamination originating from the UCAP. On the basis of the location of the pit and results from the 1981 and 1983 boreholes, an initial prior pdf was assigned to each decision point that reflected the expected probability of finding contamination at that decision point. These initial prior pdfs were then updated with the 1987 sampling data. 
The updating process requires an indicator variogram. A variogram is a function that captures the nature of the spatial autocorrelation present in a system. In general, variograms require the definition of a functional form, the range of the spatial autocorrelation, and the variance. In the case of the updating process used by PLUME, the variance of the system is not important. A variogram analysis conducted with 1987 sampling data suggested that a spherical function with a range approximately equal to $18 \mathrm{~m}(60 \mathrm{ft})$ was appropriate for the UCAP. A variogram's range need not be identical in all directions. Variograms can have their own particular spatial orientation. For example, a contamination event might show much stronger autocorrelation in its horizontal distribution as compared to its vertical distribution. A case like this would give rise to anisotropic variograms. The variogram analysis conducted on the 1987 data showed no signs of anisotropy.

Two sampling programs were conducted as part of the MWLID in the summer of 1992. First, two boreholes associated with the Thermally Enhanced Vapor Extraction System (TEVES) north of the unlined chromic acid pit (TEVES-1 and TEVES-2) were completed. Second, three additional boreholes were installed along the western boundary of the pit (UCAP-1, UCAP-2, and UCAP-3). After each sampling program, an impact surface was created with PLUME to determine the areas where maximum impact on contaminant delineation could be expected if additional boreholes were installed. The impact at specific locations was measured as the expected number of decision points currently classified as state uncertain that would be reclassified as either clean or contaminated given a new vertical soil borehole at that location. In Figure 7, impact is gray-scale coded and ranges from white (minimum impact) to black (maximum impact). On the basis of 1987 data alone, the regions with the greatest potential for new borehole locations lie north and south of the pit. With the completion of the first two TEVES boreholes, the value of additional boreholes north of the pit is insignificant compared to the value of additional boreholes south of the pit. After the final three UCAP boreholes were drilled, it was determined that should any additional sampling be conducted, the most valuable area is southeast of the pit.

After each sampling program, PLUME used the additional sampling data to reclassify each decision point as either clean (less than 0.2 chance of contamination), contaminated (greater than 0.8 chance of contamination), or state uncertain (probability of contamination between 0.2 and 0.8 ). The choice of 0.8 as a probability threshold was arbitrary for the purposes of the retrospective study. In an actual site characterization, this value would be negotiated with the regulatory agency. Figure 8 graphically shows how allocation of decision points to these categories changed as each sampling program was completed. The 0.5 line indicates the percent of decision points that would have been categorized as contaminated if a decision point had probability of contamination greater than 0.5. This is equivalent to forcing a clean/contaminated decision at each decision point, regardless of the probability of erroneous classification. Finally, Figure 9 shows how the horizontal extent of contamination looks at a depth of approximately $6 \mathrm{~m}(20 \mathrm{ft})$ after each sampling program. The shading in Figure 9 ranges from white (zero probability of contamination) to black (probability of contamination equal to one). 


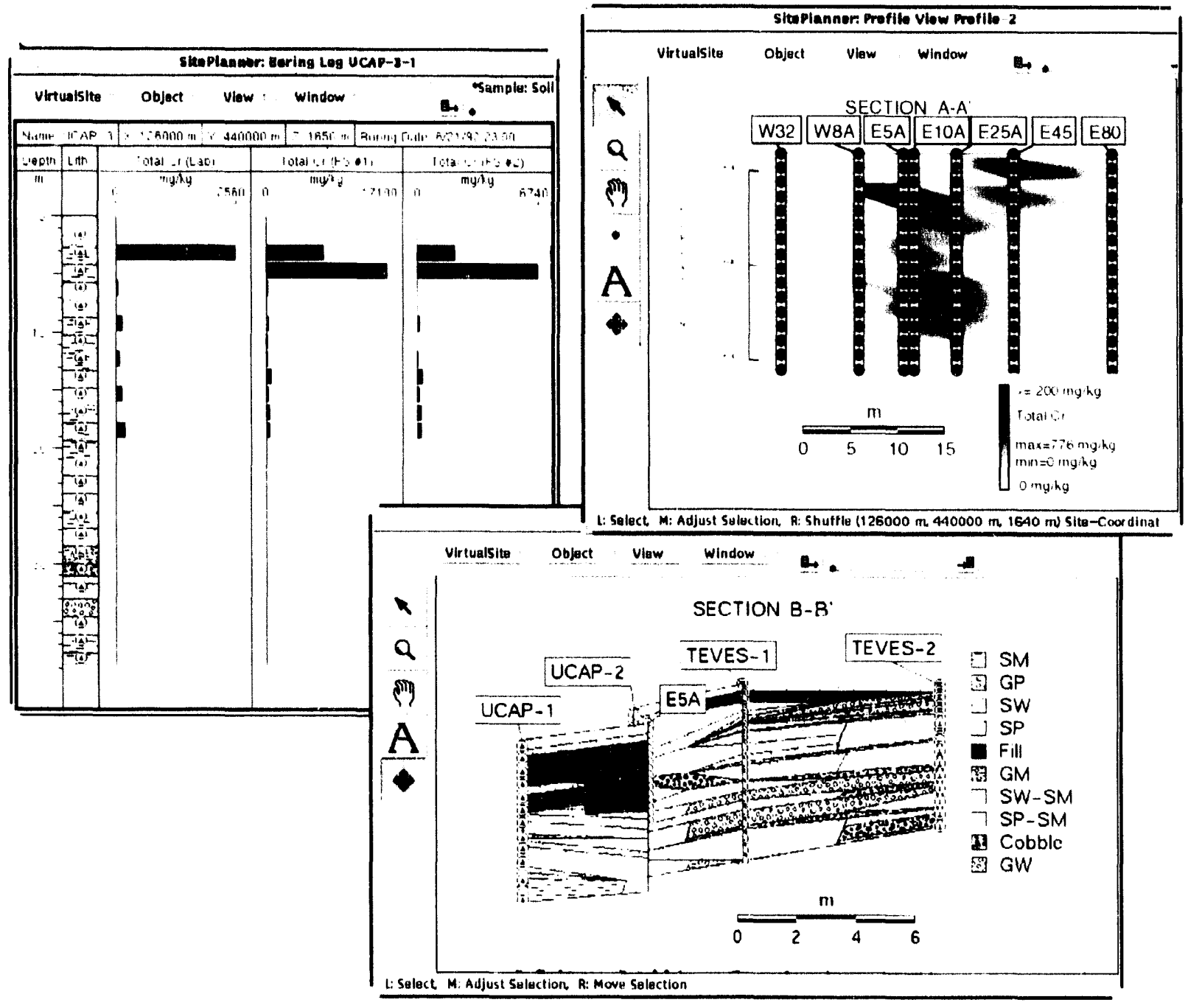

FIGURE 6 Site Planner ${ }^{\mathrm{TM}}$ as Data Visualizer

The 1987, TEVES and UCAP sampling programs consisted of 12 boreholes and 197 samples. An obvious retrospective question is, if the original program had been designed to limit the number of sampling programs, boreholes, and sampling points by using the proposed methodology, how well could one have done? By using the same initial prior pdfs for each decision point, a set of five boreholes was located and samples placed along their vertical length so that the maximum impact on the percent of decision points categorized as state uncertain was obtained. Figure 10 shows the locations of these 5 boreholes relative to the 12 boreholes that were actually drilled. On the basis of the initial prior pdfs for the set of decision points, approximately $68 \%$ of the decision points would have been classified as state uncertain. Upon completion of the three sampling programs actually conducted, this value was reduced to $32 \%$. 


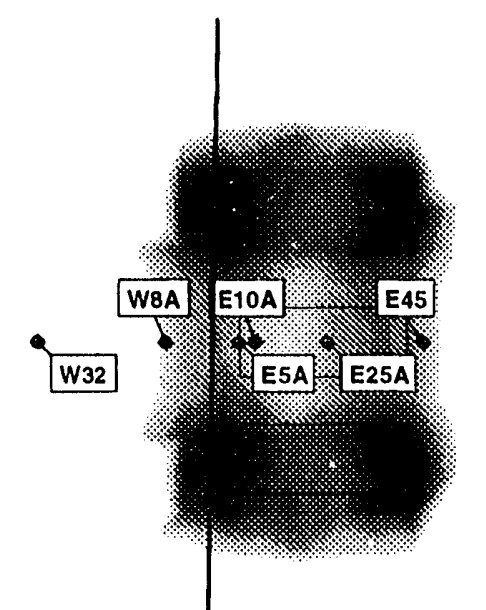

post-1987 impact $(\min =-7.60, \max =6.20)$

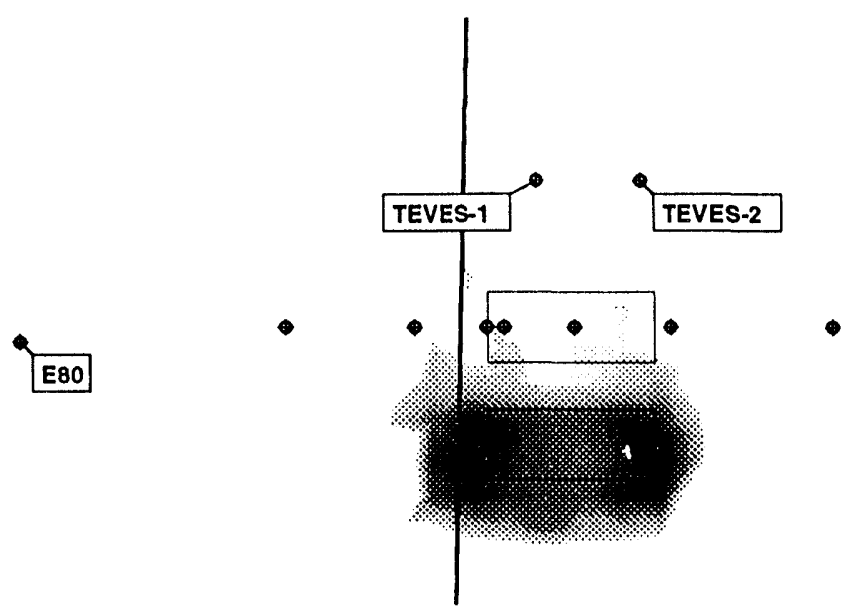

post-TEVES impact $(\min =-7.73, \max =5.81)$

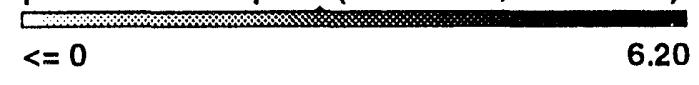

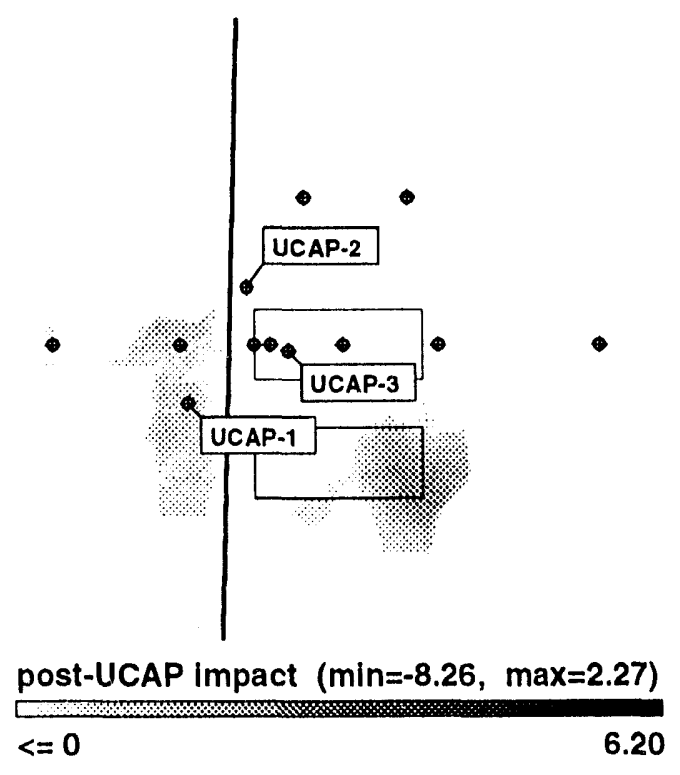

FIGURE 7 Expected Impact of New Vertical Bores

In contrast, by using PLUME to strategically place the five boreholes, resulting in a total of 35 samples, the number of decision points classified as uncertain could be dropped to $14 \%$. In addition to having a substantially greater impact than the actual sampling programs, this would have represented a $66 \%$ savings in sampling program mobilization costs, a 58\% savings in borehole costs, and an $82 \%$ savings in sample analysis costs (assuming the analyses were done in a laboratory by techniques comparable to those used during the actual sampling programs). If field screening techniques had been used on the majority of samples, with only a few sent to the laboratory for confirmatory analysis, the savings in sample analysis costs would have been even greater. Finally, in terms of time taken to characterize the site, the characterization process would have been completed in one drilling program rather than three. 


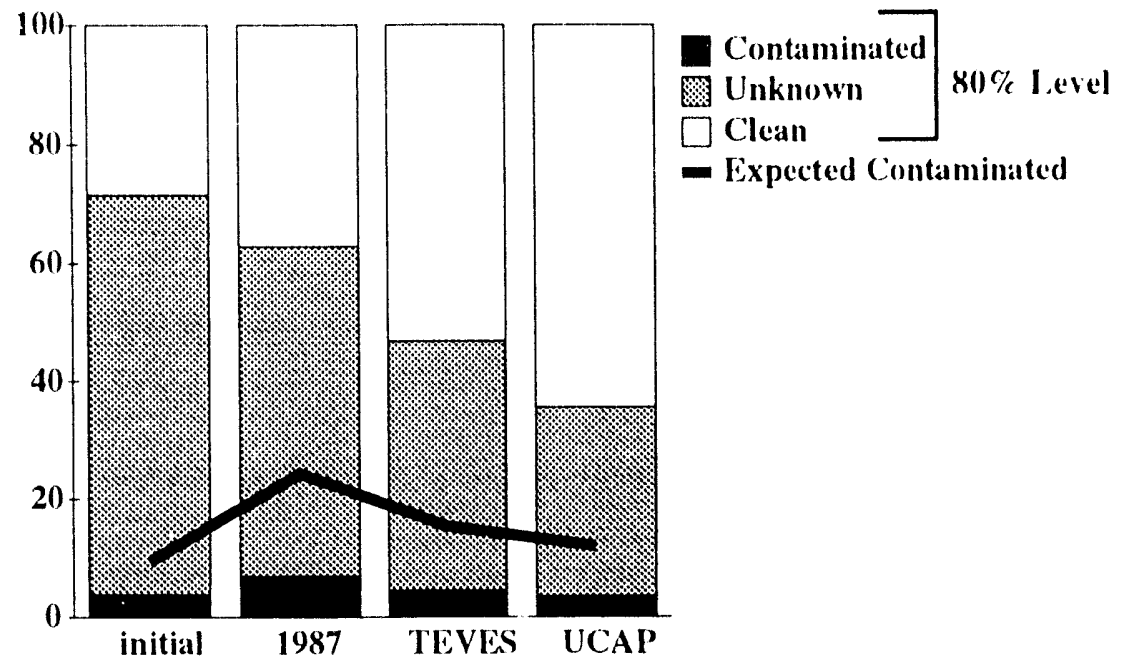

FIGURE 8 Classification of UCAP Decision Points
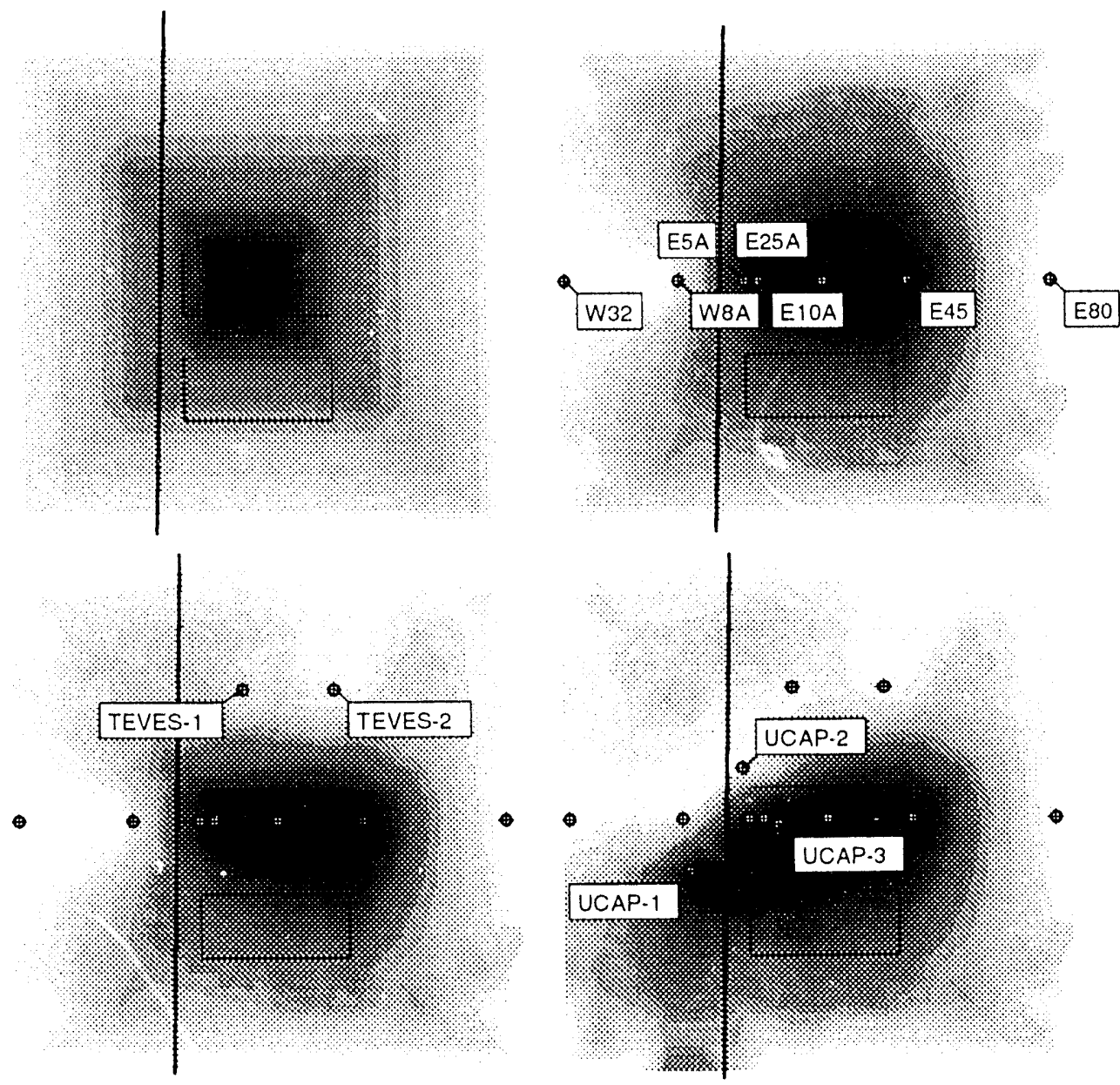

Contamination Probability

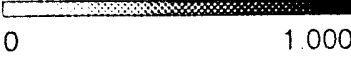

FIGURE 9 Lateral Contamination at a Depth of $6 \mathbf{m}$ 


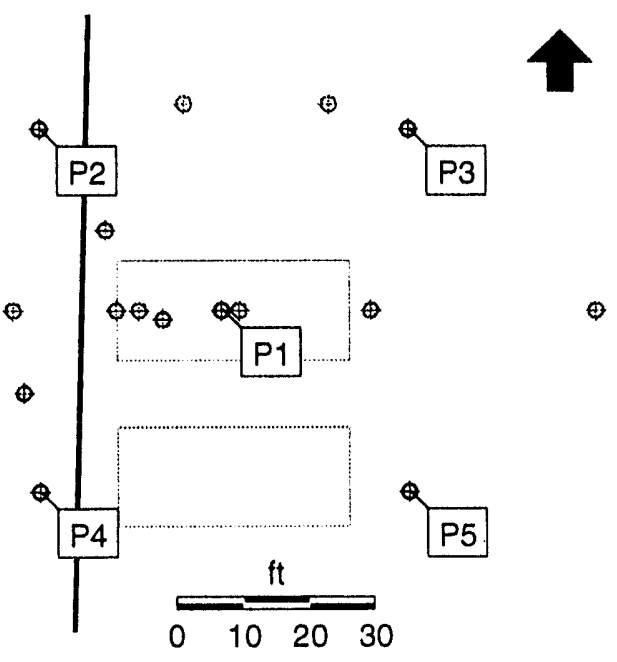

FIGURE 10 Recommended Vertical Bore Locations 


\section{APPROACH LIMITATIONS}

\section{*}

The approach described in this report does have limitations. SitePlanner ${ }^{\mathrm{TM}}$ cannot work with raster images of sites such as those that might be generated by aerial photographs or satellite images. SitePlanner ${ }^{\mathrm{TM}}$ is capable of efficiently handling sites with objects that number in the thousands. For sites with larger data sets, there is a significant deterioration in software performance. This limitation means that SitePlanner ${ }^{\mathrm{TM}}$ cannot effectively handle continuous or near-continuous data, such as those that might be generated by a nonintrusive geophysical survey or a down-hole sensor. This also places a limit on the size of the grid that SitePlanner ${ }^{\mathrm{TM}}$ can effectively work with when supporting PLUME. At the UCAP, initial attempts with a fine, four-foot spacing between decision points resulted in a grid with approximately 30,000 nodes. This proved too great a number for SitePlanner ${ }^{\mathrm{TM}}$, and the grid was consequently changed to an eight-foot spacing between nodes, reducing the total number of grid nodes to 4,000. The various subsurface views of SitePlanner ${ }^{\mathrm{TM}}$ were designed for vertical boreholes. Consequently, some manipulation of the data dictionary was required to accommodate the slant and direction of the boreholes drilled by the MWLID. Finally, the stratigraphic interpolation performed by SitePlanner ${ }^{\mathrm{TM}}$ when displaying profile views and fence diagrams does not always provide plausible displays of stratigraphic structure. While more sophisticated and interactive stratigraphic modeling can be done using SitePlanner ${ }^{\mathrm{TM}}$, it is not amenable to rapid site visualization. As part of the MWLID, SitePlanner ${ }^{\mathrm{TM}}$ limitations were discussed with ConSolve, Inc., the vendor. A second release of SitePlanner ${ }^{\mathrm{TM}}$, currently under development, will address these limitations.

PLUME has its own limits of applicability. PLUME is based partially on geostatistical analysis. PLUME assumes a stationary covariance structure over the region of analysis. PLUME also assumes that the covariance structure is known and can be modeled. When hard data already exist for a site, such as at the UCAP, a preliminary variogram analysis can be performed that identifies the most likely variogram functional form and its range. These can be modified as more data are collected. A logical extension of PLUME's Bayesian perspective would treat the underlying variogram and its parameters in a Bayesian sense, subject to automatic updating as new data become available. Currently, PLUME lacks this capability. When little hard data are initially present, PLUME's analysis is driven by the user's interpretation of the soft information available. Two analysts with differing interpretations of initial soft information can use PLUME with the same data set and draw very different conclusions. As more sard data become available, this differing interpretation becomes less of an issue because the hard data eventually dominate the soft information in the analysis. In any case, this points to the need for negotiation and consensus between environmental restoration staff, responsible parties, and regulators both in DQO formulation and in the initial analysis of soft information available for a site. The methodology employed by PLUME is numerically intensive. Depending on the size of the decision point grid, the range of the variogram in use, and the amount of hard information available, PLUME can take significant amounts of computer time to arrive at solutions. From an adaptive sampling program perspective, analysis results must be available in near 
real time if they are to have a bearing on the course of the sampling program. Finally, PLUME provides estimates of contaminant extent but not of contaminant level. 


\section{CONCLUSIONS}

Adaptive sampling programs have the potential for significant cost and time savings during a site characterization process. However, adaptive sampling strategy support is required. Adaptive sampling strategy support guarantees that technical staff conducting an adaptive sampling program attain a complete understanding of their site as quickly as possible, that they have their data readily available as they are being generated, that they place their new sampling locations as best as possible, and that they stop when enough samples have been collected for their characterization purposes. SitePlanner ${ }^{\mathrm{TM}}$, an objectoriented database designed for site characterization work fulfills the role of integrating, managing, and displaying site characterization data. Smart sampling strategy methodologies (e.g., PLUME) that combine Bayesian analysis with spatial statistics provide quantitative support for estimating contaminant extent, measuring the benefits to be expected from additional sampling, and identifying where those samples should be placed.

This approach was applied in a retrospective analysis at the UCAP, part of the chemical waste landfill belonging to Sandia National Laboratories. The analysis suggests significant cost and time savings could have been realized if this approach had been adopted from the outset. 


\section{REFERENCES}

1. Journel, A.G., 1983, "Nonparametric estimation of spatial distributions," Mathematical Geology 15:445-469.

2. Johnson, R.L., 1993, "A Bayesian Approach to Contaminant Delineation," in Proceedings of the Groundwater Modeling Conference, Golden, Colo., June 9-12, 1993, E. Poeter, S. Ashlock, and J. Proud (editors), Colorado School of Mines, Golden, Colo., pp. P87-P95.

3. U.S. Environmental Protection Agency, 1987, Data Quality Objectives for Remedial Response Activities: Development Process, Office of Emergency and Remedial Response and Office of Waste Programs Enforcement, Washington, D.C.

4. U.S. Environmental Protection Agency, 1987, Data Quality Objectives for Remedial Response Activities: Example Scenario, Office of Emergency and Remedial Response and Office of Waste Programs Enforcement, Washington, D.C. 

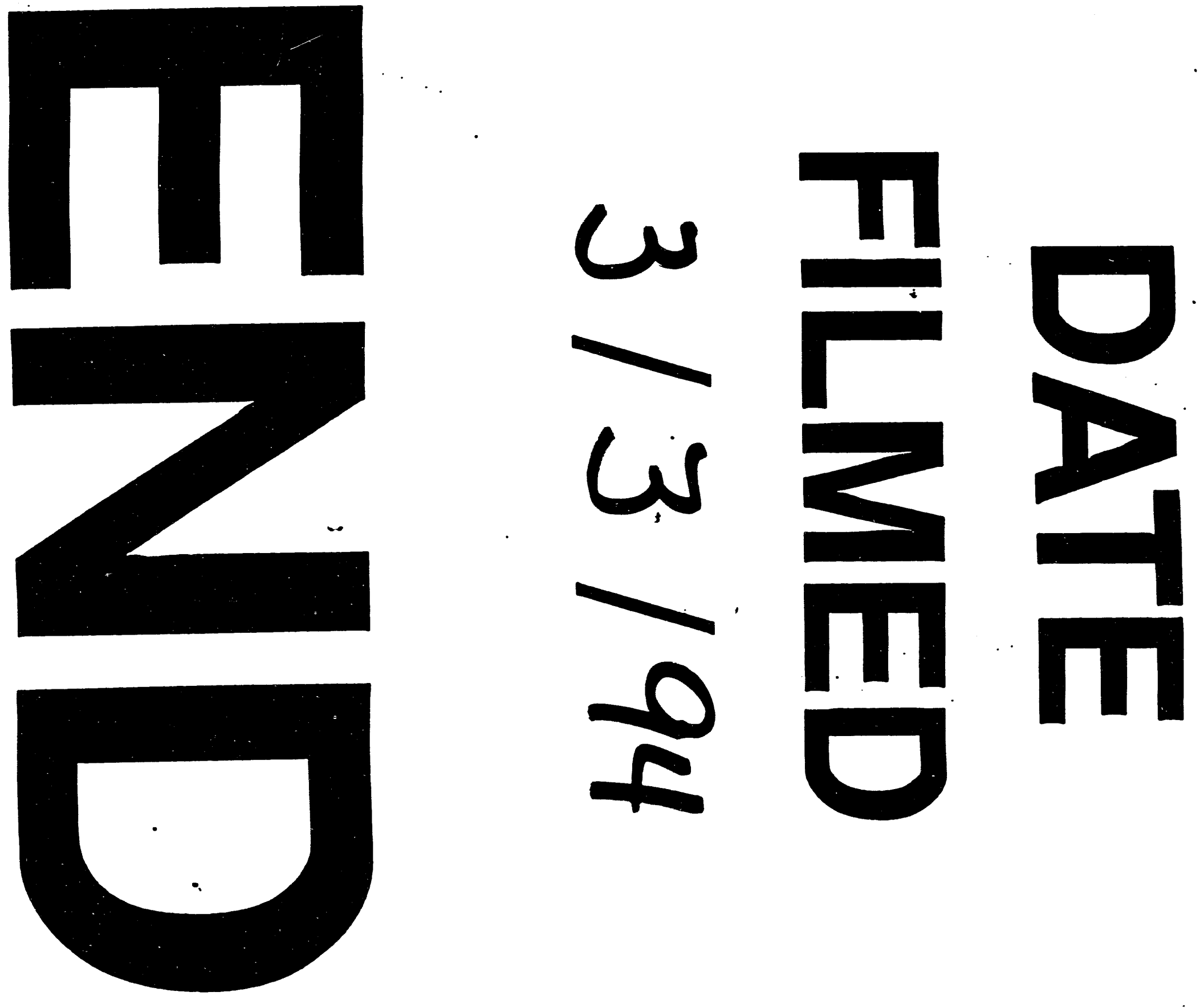


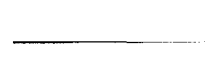

